\title{
Selective Skeletal Butene Isomerization through a Bimolecular Mechanism*
}

\author{
M. Guisnet ${ }^{1}$, P. Andy ${ }^{1}$, N. S. Gnep ${ }^{1}$, E. Benazzi ${ }^{2}$ and C. Travers ${ }^{2}$ \\ 1 UMR 6503, Catalyse en chimie organique, université de Poitiers, faculté des sciences, \\ 40, avenue du Recteur Pineau, 86022 Poitiers Cedex - France \\ 2 Institut français du pétrole, 1 et 4, avenue de Bois-Préau, 92852 Rueit-Malmaison Cedex - France \\ * Presented at the 12th International Zeolithe Conference, Baltimore, July 1998
}

\begin{abstract}
Résumé - Isomérisation bimoléculaire sélective du $n$-butene en isobutene — La transformation du $n$-butène a été étudiée en réacteur dynamique à $350^{\circ} \mathrm{C}$ sur des zéolithes à taille de pore intermédiaire (H-FER, H-TON, H-EU-1 et H-MFI) et à $500^{\circ} \mathrm{C}$ sur alumine. Sur les catalyseurs frais, l'isobutène mais aussi le propène et les pentènes sont directement formés (produits primaires), ce qui démontre que l'isomérisation de squelette du $n$-butène se produit au moins en partie par des étapes successives d'oligomérisation, isomérisation et craquage (mécanisme bimoléculaire). Les différences importantes de sélectivité entre les catalyseurs sont dues à de nombreux facteurs : participation ou non d'intermédiaires trimères, limitations dans la désorption des produits branchés, etc. Sur tous les catalyseurs, la sélectivité en isobutène augmente avec le temps de travail. Cette augmentation s'explique par un nouveau mode d'isomérisation très sélectif impliquant comme intermédiaires des triméthylpentènes formés par réaction du $n$-butène sur des molécules d'isobutène retenues dans les pores de la ferrierite. Cette réaction autocatalytique rend très sélective en isobutène la transformation bimoléculaire du $n$-butène.

Mots-clés : butènes, isomérisation de squelette, mécanisme, zéolithe, alumine, sites actifs.
\end{abstract}

\begin{abstract}
Selective Skeletal Butene Isomerization through a Bimolecular Mechanism-n-Butene transformation was carried out at $350^{\circ} \mathrm{C}$ over medium pore size zeolites (H-FER, H-TON, H-EU-I and H-MFI) and at $500^{\circ} \mathrm{C}$ over alumina. With fresh catalysts, not only isobutene but also propene and pentenes are primary products, which indicates that at least some of the butene isomerization occurs through oligomerizationisomerization-cracking steps (bimolecular mechanism). The large differences in selectivity are due to many factors, including whether or not trimer intermediates participate in the mechanism and limited product desorption. All the catalysts exhibit increasing isobutene selectivity with increasing time on-stream. This increase in selectivity can be explained by the selective isomerization of $\mathrm{n}$-butene through a reaction process whose first step is the formation of trimethylpentene intermediates from isobutene product and $\mathbf{n}$-butene reactant. This autocatalytic reaction can render the bimolecular transformation of $n$-butenes very selective to isobutene.
\end{abstract}

Keywords: $\mathrm{n}$-butène isomerization, mechanism, zeolite, alumina, active sites.

\section{INTRODUCTION}

Recent implementation of the United States Clean Air Act has increased the demand for methyl tert-butyl ether (MTBE) for use in gasoline $[1,2]$. MTBE is usually prepared through a reaction between isobutene and methanol using an ion exchange resin as catalyst. Isobutene is also required for production of ethyl tert-butyl ether (ETBE) which, like MTBE, has a high octane number. However the availability of isobutene, which is usually produced by catalytic and steam cracking, is a limiting factor for expanding the production of these ethers. This limitation can be overcome by isomerization of $n$-butane to isobutane followed by dehydrogenation to isobutene. However, the direct conversion of $n$-butene, which is also available from catalytic and steam cracking, seems to be more attractive [3].

A large variety of catalysts based on alumina [4-9] or on medium pore size zeolites [10-16] have been reported as being active in the skeletal isomerization of butene. Various processes based on these catalysts have been developed, including ISO-4 by Institut français du pétrole (IFP) [17], Lyondell Petrochemical by Shell and Lyondell [2], IsoTex by 
Texaco [18], Isofin by BP/Mobil [19], SkIP by Texas Olefins and Phillips Petroleum [20]. Alumina catalysts should operate at high temperature $\left(450-500^{\circ} \mathrm{C}\right)$ and in the presence of water, while zeolite catalysts operate at lower temperature and without water.

The skeletal isomerization of $n$-butenes through acid catalysis, compared to that of larger $n$-alkenes, has distinctive features [21 and 22]. Indeed, the monomolecular isomerization mechanism necessarily involves a very unstable primary carbenium ion:

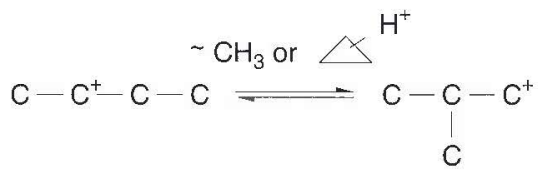

which is not the case for the isomerization of larger hydrocarbons:

$$
\mathrm{C}-\mathrm{C}^{+}-\mathrm{C}-\mathrm{C}-\mathrm{C} \rightleftharpoons \underset{\mathrm{C}}{\aleph_{\mathrm{C}}^{\mathrm{H}^{+}}} \mathrm{C}-\mathrm{C}-\mathrm{C}
$$

Consequently, when a relatively high reactant pressure is used, butene isomerization occurs through a bimolecular mechanism involving very simple octene dimerization, skeletal isomerization and cracking reactions, via secondary and tertiary carbenium ions.

Through this mechanism, propene + pentenes are formed simultaneously with isobutene. Indeed dimethylhexenes $\left(\mathrm{DMC}_{6}{ }^{=}\right)$and trimethylpentenes $\left(\mathrm{TMC}_{5}{ }^{\circ}\right)$, which are the most likely octene intermediates, undergo cracking not only into isobutene but also into propene plus pentenes. Moreover, the other possible $\mathrm{C}_{8}$ intermediates - methylheptenes $\left(\mathrm{MC}_{7}{ }^{2}\right)$ formed from dimerization of 1-butene - can only be cracked into propene and pentenes (Fig. 1). Therefore the simultaneous formation of isobutene and propene + pentenes constitutes a strong argument in favor of the bimolecular mechanism in butene isomerization [16].

However, butene isomerization can occur either solely through the bimolecular mechanism or partly through this mechanism and partly through the monomolecular mechanism which does not allow propene and pentenes to form. Unfortunately, in this latter case, the degree of participation of the two mechanisms cannot be estimated, as the selectivity of the bimolecular mechanism depends on various parameters. Indeed, it can be expected that the relative rates of the various dimerization, isomerization and cracking steps involved in the bimolecular mechanism (Fig. 1) vary significantly with the operating conditions (temperature and pressure) as well as with the acidity and the pore structure of the catalyst. Therefore, a low selectivity to propene plus pentenes is not necessarily the consequence of a predominant monomolecular isomerization process.
However, certain authors consider that the prevailing mechanism of skeletal butene isomerization is monomolecular $[13,23]$, the bimolecular mechanism only being responsible for the secondary transformation of isobutene into propene and pentenes.

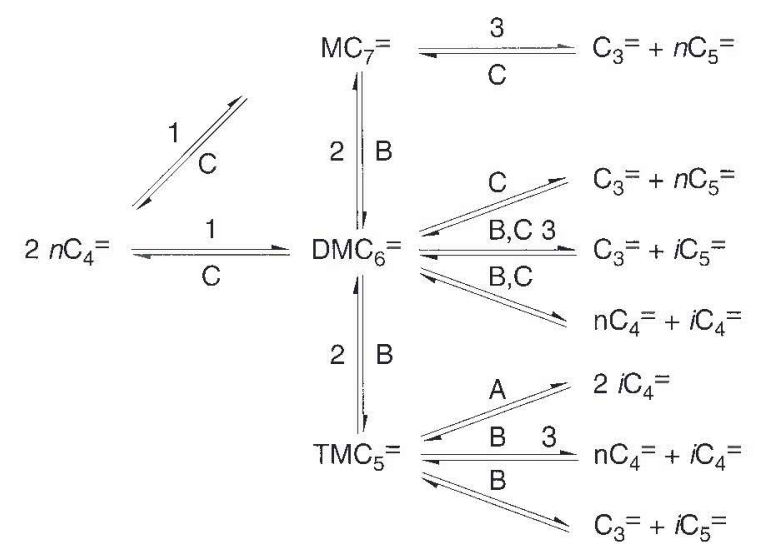

$\mathrm{MC}_{7}{ }^{-}$: methylheptenes, $\mathrm{DMC}_{6}=$ : dimethylhexenes,

$\mathrm{TMC}_{5}=$ : trimethylpentenes

In this paper, we show from the investigation of butene isomerization over medium pore size zeolites and over alumina that a bimolecular mechanism can allow selective transformation of $n$-butene into isobutene.

\section{EXPERIMENTAL}

FER, TON and EU-1 samples with $\mathrm{Si} / \mathrm{Al}=13.8,37.5$ and 18.1, respectively were synthesized at the Laboratoire des matériaux minéraux in Mulhouse, France. MFI zeolite with $\mathrm{Si} / \mathrm{Al}=36.8$ was purchased from $P Q$ Corporation. The alumina catalyst was supplied by IFP. Before being used, all the catalyst samples were in situ calcined at $500^{\circ} \mathrm{C}$ under dry air flow $\left(60 \mathrm{ml} \cdot \mathrm{min}^{-1}\right)$ for 10 hours. The transformation of 1-butene was carried out in a flow reactor with nitrogen as the carrier gas and $\mathrm{N}_{2} / 1$-butene molar ratio $=9$. Reaction products were analyzed on-line by gas chromatography using a FID detector and a $50 \mathrm{~m}$ chrompack PLOT $\mathrm{Al}_{2} \mathrm{O}_{3} / \mathrm{Na}_{2} \mathrm{SO}_{4}$ capillary column.

\section{RESULTS AND DISCUSSION}

\subsection{Demonstration of the Participation of a Bimolecular Mechanism in $\mathbf{n}$-Butene Isomerization over Fresh Catalysts}

The selectivity was determined over a large range of conversions by operating at a time on-stream value of $5 \mathrm{~min}$ for various contact times. Whatever the catalyst and the contact time, the distribution of linear butenes is close to that at thermodynamic equilibrium, which means that the double 
Dimerization (1) and Cracking (3) steps: Steps A involve two tertiary carbenium ions as intermediates, steps B one tertiary and one secondary, steps $\mathrm{C}$, two secondary carbenium ions. $\mathrm{A}$ is faster than $\mathrm{B}$ which is faster than $\mathrm{C}$ :

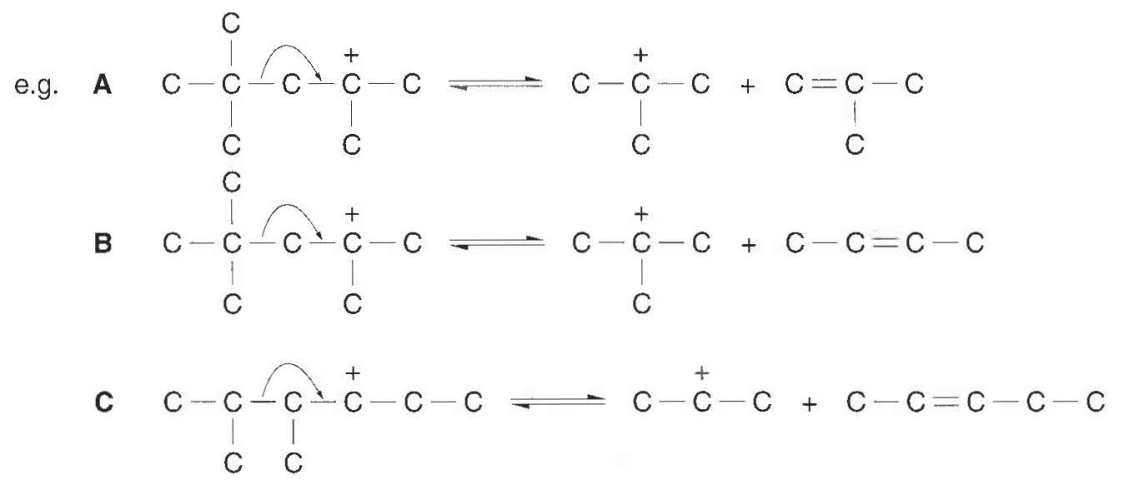

Isomerization steps (2): Alkyl shifts (type A) are responsible for isomerization without a change in the chain length:

e.g.<smiles>CCC(C)[CH-]C(C)C=CCC[C]1CC1C(C)C</smiles>

Changes in the chain length occur (more slowly) via protonated cyclopropane intermediates (type B)

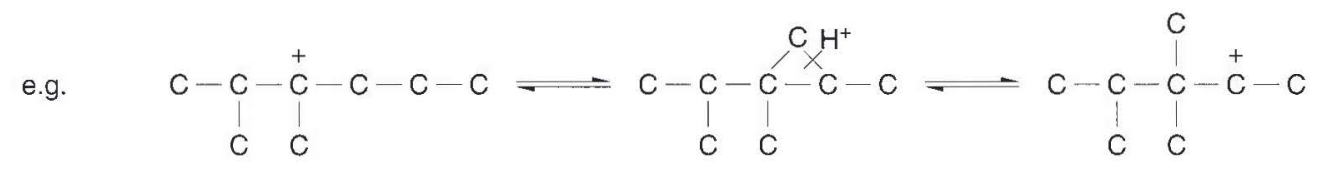

Figure 1

Transformation of $n$-butene through the dimerization (1) - isomerization (2) - cracking (3) mechanism (bimolecular mechanism),

bond shift is much faster than the other reactions. Therefore, all linear butenes can be considered to be the feed and it is their conversion into the other products, and not that of 1-butene, which will be considered.

Product distributions at zero conversion, the initial distributions, were estimated by extrapolating the curves of selectivity as a function of conversion, such as those given in Figure 2 for isobutene and propene plus pentenes. With all the catalysts, isobutene, propene and pentenes are formed directly. Octenes and $n$-butane are also primary products with all the medium pore size zeolites. Moreover, with EU-1, MFI and, to a limited extent, with TON, hexenes and heptenes are also directly formed (Table 1). With alumina, octenes appear to be secondary products while $n$-butane, butadiene and methane are directly formed. Ethane, propane, isobutane, pentanes and ethene, hexenes and heptenes, except with EU-1, MFI and TON, are secondary products.

As is indicated in the introduction, the simultaneous direct production of isobutene, propene and pentenes found with all samples is a strong argument in favor of the partial or total participation of a bimolecular mechanism in $n$-butene isomerization. However the mechanism involving dimerization, isomerization and cracking reactions in succession cannot explain the formation of hexenes and heptenes as primary products over H-MFI, H-EU-I and, to a limited extent, over H-TON. The direct formation of these products can only be explained by the formation of trimer intermediates.

$$
3 n \mathrm{C}_{4}=\mathrm{C}_{12}=\longrightarrow \begin{aligned}
& \mathrm{C}_{3}=+\mathrm{C}_{9}=\mathrm{C}_{3}=+\mathrm{C}_{6}= \\
& \mathrm{C}_{4}=+\mathrm{C}_{8}=\mathrm{C}_{3}=+\mathrm{C}_{5}= \\
& \mathrm{C}_{5}=+\mathrm{C}_{7}=\mathrm{C}_{3}=+\mathrm{C}_{4}= \\
& \mathrm{C}_{6}=+\mathrm{C}_{6}=2 \mathrm{C}_{3}=
\end{aligned}
$$



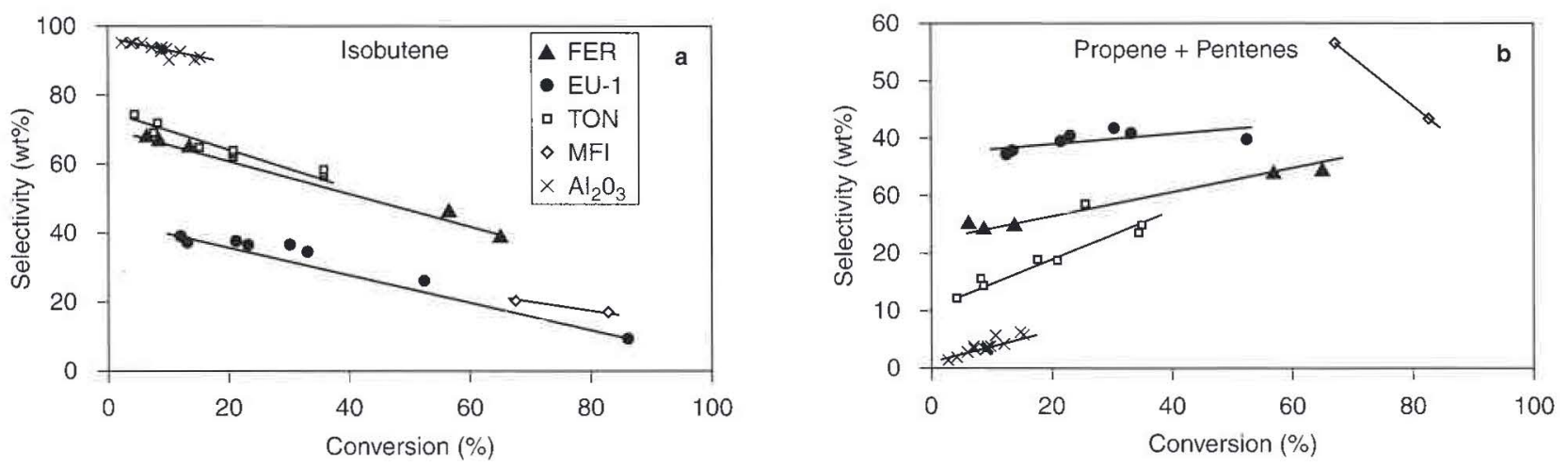

Figure 2

Selectivity to isobutene (a), propene plus pentenes (b) during $n$-butene transformation over FER, EU-1, TON, MFI and alumina.

TABLE 1

Initial product distribution (wt $\%$ ) at 5 min reaction (and at $1.5 \mathrm{~min}$ )

\begin{tabular}{l|c|c|c|c|c|c|c}
\hline Zeolite & $\left.\mathrm{iC}_{4}{ }^{(*}\right)$ & $\mathrm{C}_{3}=$ & $\mathrm{C}_{5}=$ & $\mathrm{C}_{8}=$ & $\mathrm{C}_{6}=$ & $\mathrm{C}_{7}=$ & $n \mathrm{C}_{4}$ \\
\hline FER & $70.5(44.3)$ & 15.7 & 9 & 0.3 & 0 & 0 & 4.5 \\
EU-1 & $43.5(26.6)$ & 15.5 & 22 & 12 & 3.5 & 2 & 1.5 \\
TON & $76.8(54.7)$ & 6 & 5.5 & 7 & 0.5 & 0.2 & 4 \\
Alumina & $95.9(75)$ & 1.7 & 1.7 & 0.1 & 0.2 & 0 & 0.3 \\
\hline
\end{tabular}

This formation of trimers, which is most likely responsible for the low selectivity to isobutene of H-MFI and H-EU-1, cannot occur in the pores of H-FER and is slow with H-TON because of the narrow space available near its acid sites. It does not occur with alumina because of its low acidity and the adverse thermodynamic equilibrium at high temperature [8].

Large differences are also observed in the formation of octenes. With FER and alumina practically no octenes appear in the gas phase. With alumina, this is due to the low percentage of dimers at thermodynamic equilibrium at $500^{\circ} \mathrm{C}$ [8], while with FER this can be explained by the difficulty, or even impossibility, of desorption of dimethylhexenes and trimethylpentenes [14].

From this study it can be concluded that on the fresh catalysts at least some of the $n$-butene isomerization occurs through an oligomerization-isomerization-cracking mechanism. The large differences in initial selectivity can be explained either by differences in the relative significance of mono- and bimolecular mechanisms or, if only the oligomerization-isomerization-cracking mechanism participates in butene isomerization, by differences in the oligomer intermediates. Indeed the oligomer intermediates can be composed solely of octenes (H-FER, alumina) or of octenes plus dodecenes (H-EU-1, H-MFI and H-TON). Moreover, even in the first case, the distribution of octenes depends on the rate of the various reactions of figure 1 , hence on the physicochemical characteristics of the catalyst (acidity, porosity) and on the operating conditions.

\subsection{Origin of the Increase with Time On-Stream of the Selectivity to Isobutene}

Whatever the catalyst and the contact time, an increase in the selectivity to isobutene, taken as the percentage of isobutene in the products of $n$-butene transformation is observed (Fig. 3). If both mono- and bimolecular mechanisms participate in butene isomerization, the preferential deactivation by coking of the acid sites responsible for the bimolecular reaction could explain this increase in selectivity. However, this explanation is unlikely. Indeed, deactivation by coke preferentially affects the strongest acid sites [24], and it seems quite abnormal that the facile bimolecular isomerization would be favored on the strongest acid sites over the energetically less likely monomolecular isomerization.

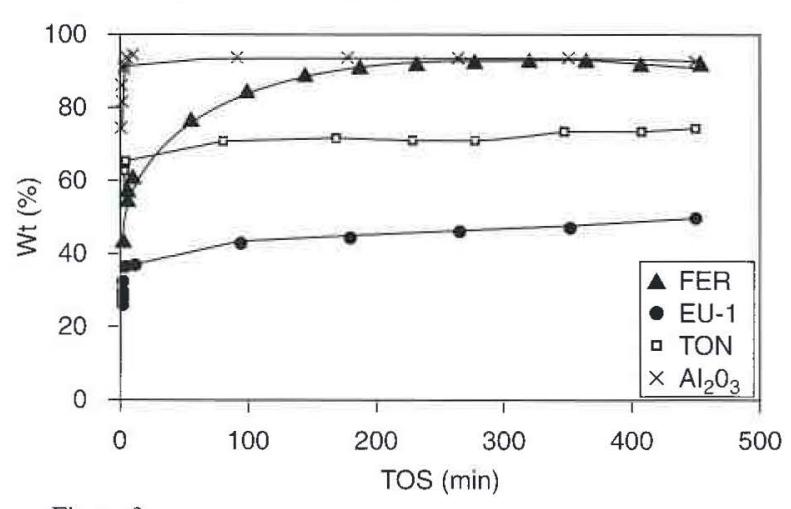

Figure 3

Selectivity to isobutene as function of time on-stream (TOS).

Another argument against this proposal is that the increase in isobutene selectivity is due not only to a decrease in the formation of propene and pentenes but also to an increase in the formation of isobutene, and this even at low conversion [25] (Fig. 4). According to the supporters of the 

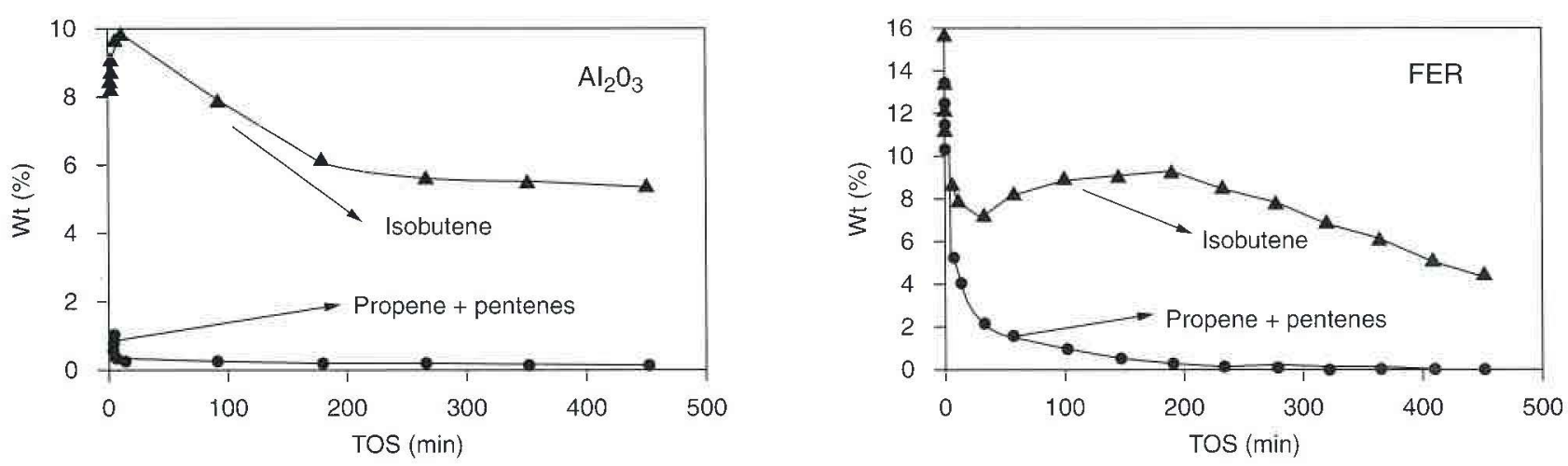

Figure 4

Isobutene yield as function of time on-stream (TOS).

monomolecular mechanism [13, 23, 26, 27], this increase in the yield in isobutene, i.e., the conversion of $n$-butene into isobutene, would be due to the suppression of the secondary transformations of isobutene. However, this seems most unlikely as the formation of propene plus pentenes is slower from isobutene than from $n$-butenes. This was shown, in particular, with alumina [17] and with H-FER [16]. The formation of carbonaceous compounds (coke) was also found to be slower from isobutene than from $n$-butenes [28].

It should be emphasized that, unexpectedly, the increase in isobutene yield observed with H-FER when time on-stream increased from 40 to $200 \mathrm{~min}$ (Fig. 4) occurs despite a large increase in the carbonaceous deposits (from 2.5 to $6.2 \mathrm{wt} \%)$. These carbonaceous deposits significantly block access to the pores. Indeed the pore volume accessible to nitrogen, hence to the reactant, passes from $80 \%$ of the pore volume of the fresh H-FER to $20 \%$ [25]. This is why we have suggested that the carbonaceous compounds blocked in the zeolite pores played a role in butene isomerization over aged ferrierite samples. This reaction would occur with high selectivity through a pseudo-monomolecular mechanism involving tertiary [25] or benzylic carbocations [34] formed from carbonaceous compounds [25]. However, it has been recently shown that besides these carbonaceous compounds, reaction products, especially isobutene, were retained inside the pores during the reaction [29]. This led us to propose that at least at short time on-stream, the increase in isobutene yield was due to an autocatalytic reaction, $n$-butene isomerization occurring on tert-butyl carbenium ions formed by adsorption of isobutene on the protonic sites of this zeolite. Indeed, this isomerization involves more facile steps (B alkylation, A isomerization and A cracking) than the bimolecular isomerization of $n$-butene ( $\mathrm{C}$ alkylation, $\mathrm{B}$ isomerization and A, B, C cracking (Fig. 1)). Moreover, it is very selective, as the formation of propene and pentenes involves one A isomerization and one B cracking step instead of one A cracking step, which is much faster [31], for isobutene formation. This autocatalytic reaction allows rapid and selective transformation of one molecule of $n$-butene into one molecule of isobutene. This is a pseudo-monomolecular process, which could, therefore, explain why no ${ }^{13} \mathrm{C}$ scrambling is observed in $n$-butene isomerization over aged FER samples $[32,33]$. The maximum observed in the isobutene yield in the case of alumina (Fig. 4) can also be related to its autocatalytic reaction.

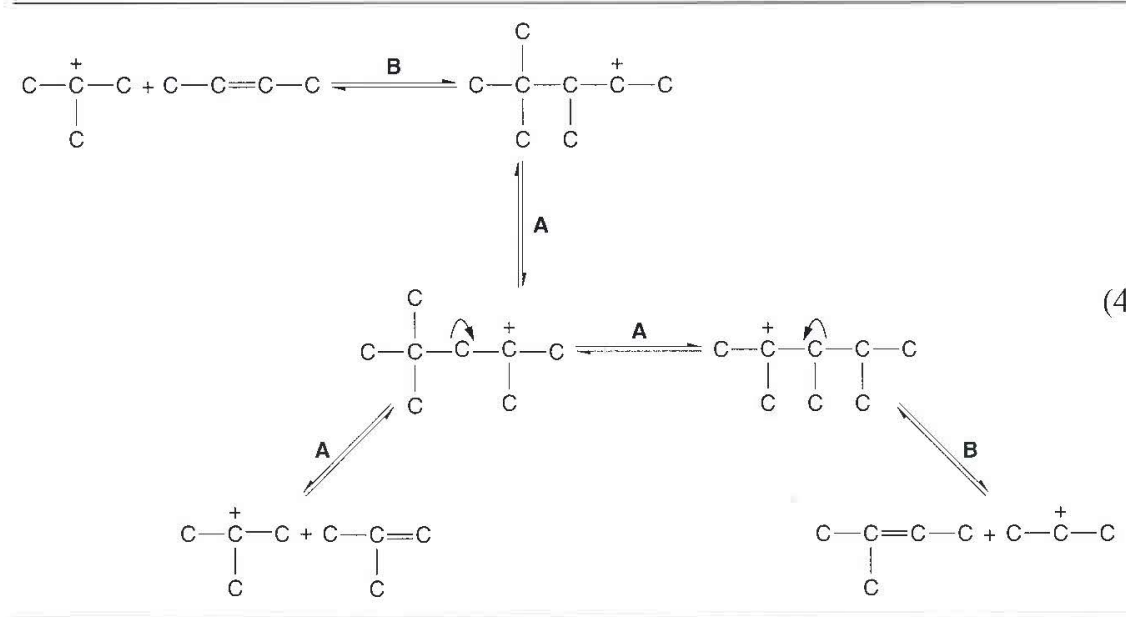

Alkylation and cracking steps: $\mathbf{A}$ involves two tertiary carbenium ions; $\mathbf{B}$ one tertiary and one secondary carbenium ions. A isomerization step involves alkyl shift [30]. 


\section{CONCLUSION}

The investigation of $n$-butene isomerization over medium pore size zeolites and alumina catalysts shows that on all the fresh samples at least some of the reaction occurs through a bimolecular mechanism. This bimolecular transformation of $n$-butene is necessarily accompanied by a selective formation of isobutene involving a first step in which trimethylpentene intermediates are formed from $n$-butene reactant and isobutene product. Differences in selectivity to isobutene can be attributed to various factors, including the intermediates involved in the bimolecular mechanism (dimers, trimers), limitations in the desorption of octene intermediates and how strongly isobutene molecules retained on the catalyst. In particular a very high selectivity to isobutene can be found when trimers cannot be formed and when octene intermediates cannot be formed in large quantities (e.g. on alumina because of the high reaction temperature) or cannot desorb from the pores (e.g. H-FER).

\section{REFERENCES}

1 Maxwell, I. E., Naber, J.E., and de Jong, K. P. (1994) Appl. Catal., A: General, 113, 153.

2 Wise, B.J., and Powers, D. (1994) in Environmental Catalysis (J.N. Armor, Ed.). ACS Symposium Series, 552, Ch. 22, 273.

3 Torck, B. (1997) L'Act. Chim., 4, 3.

4 Butler, A.C., and Nicolaides, C.P. (1993) Catal. Today, 18, 443.

5 Choudhary, V.R., and Doraiswamy, L.K. (1971) J. Catal., 23,54 .

6 Juguin, B., and Miguel, J. (1982) European Patent No. 66485, Institut Français du Pétrole.

7 Cheng, Z.X., and Ponec, V. (1994), J. Catal., 148, 607.

8 Szabo, J., Perrotey, J., Szabo, G., Duchet, J.C., and Cornet, D. (1991) J. Mol. Catal., 67, 76.

9 Catani, R., Cornaro, U., Miglio, R., Piccoli, V., Rossini, S., Finochio, E., and Busca, G. (1997) in International Symposium on Acid-Base Catalysis III - Book of Abstracts Rolduc, $\mathrm{O} 26$.

10 Houzvicka, J., Hansildaar, S., and Ponec, V. (1997), J. Catal. 167, 273.

11 Millini, R., and Rossini, S. (1997), in Progress in Zeolite and Microporous Materials (H. Chon, S.K. Ihm and Y.S. Uh, Eds.). Stud. Surf. Sci. Catal., 105, 1389, Elsevier, Amsterdam.

12 Mériaudeau, P., Anh, T. Vu., Le Ngoc, H., and Naccache, C. (1997) in Progress in Zeolite and Microporous Materials (H. Chon, S. K. Ihm and Y. S. Uh, Eds.). Stud. Surf. Sci. Catal., 105, 1373, Elsevier, Amsterdam,.

13 Asensi, M.A., Corma, A., and Martinez, A. (1996) J. Catal., 158,561 .
14 Mooiweer, H.H., de Jong, K.P., Kraushaar-Czarnetzki, B., Storck, W. H. J., and Krutzen, S.C.H. (1994) in Zeolites and Related Microporous Materials: State of the Art 1994 (J. Weitkamp, H.G., Karge, H. Pfeifer, and H. Holderich, Eds.). Stud. Surf. Sci. Catal., 84, 2327, Elsevier, Amsterdam.

15 O'Young, C.L., Pellet, R.J., Casey, D.G., Ugolini, J.R., and Sawicki, R.A., J. Catal., 151, 467.

16 Guisnet, M., Andy, P., Gnep, N. S., Benazzi, E., and Travers, C. (1996) J. Catal., 158, 551.

17 Amigues, P., Duplan, J.L, Legall, R., and Travers, C. (1995), presented at AIChE National Spring Meeting, Houston, March 1995.

18 Sawicki, R.A., Pellet, R. J., Kuhlmann, E.J., Huang, H.M, O'Young, C.L., Kessler, R.V., and Casey, D.G. (1995) presented at NPRA Annual Meeting, San Francisco, March 1995.

19 Ambler, C.P., Kumar Kunchal, S., and Dwyer, F.G. (1993), presented at 1993 Dewitt Petrochemical Review, Houston, March, 1993.

20 John, T.P., and Thomas, S.P. (1993), Oil and Gas Journal, 56, 24 May.

21 Brouwer, D.M. (1968) Rec. Trav. Chim., 87, 1435, Netherlands.

22 Chevalier, F., Guisnet, M., and Maurel, R. (1976) in Proceedings, 6th International Congress on Catalysis, London, 1976 (G. C. Bond, P. B. Wells, F. C. Tompkins, Eds.), 1, 478, The Chemical Society, London.

23 Houzvicka, J., and Ponec, V. (1997) Ind. Eng. Chem. Res., $36,1424$.

24 Guisnet, M., and Magnoux, P. (1997) Catal. Today, 36, 477.

25 Guisnet, M., Andy, P., Gnep, N.S., Travers, C., and Benazzi, E. (1995) J. Chem. Soc., Chem. Commun., 1685.

26 Xu, W.Q., Yin, Y.G., Suib, S.L., and O'Young, C.L. (1995) J. Phys. Chem., 99, 9443.

27 Meriaudeau, P., Naccache, C., Le, H.N., and Vu, T.A. (1997) J. Mol. Catal. A: Chemical, 123, L1.

28 Andy, P., Gnep, N.S., Benazzi, E., Travers, C., and Guisnet, M., unpublished results.

29 Guisnet, M., Andy, P., Boucheffa, Y., Gnep, N.S., Travers C., and Benazzi, E. (1998), Catal. Lett., 50, 159.

30 Jacobs, P.A., and Martens, J. (1991) in Introduction to Zeolite Science and Practice, (H. van Bekkum, E.M. Flanigen and J.C. Jansen, Eds.). Stud. Surf. Sc. Catal., 58, 445, Elsevier, Amsterdam.

31 Alvarez, F., Ribeiro, F.R., Perot, G., Thomazeau, C., and Guisnet, M. (1996). J. Catal, 162, 179.

32 Meriaudeau, P., Bacaud, R., Ngoc Hung, L., and Vu, Anh. T. (1996) J. Mol. Catal. A: Chemical, 110, L177.

33 de Jong, K.P., Mooiweer, H.H., Buglass, J.G., and Maarsen, P.K. (1997) in Catalyst Deactivation 1997 (C.H. Bartholomew, and G.A. Fuentes, Eds.). Stud. Surf. Sci. Catal., 111, 127, Elsevier, Amsterdam.

34 Andy, P., Gnep, N.S., Guisnet, M., Benazzi, E., and Travers, C. (1998) J. Catal., 173, 322.

Final manuscript received in September 1998 